\title{
Perception of Beneficiaries about Impact of Mgnregs on Economic, Social and Societal Empowerment
}

\author{
Subir Kumar Sinha* and Siddhartha D. Mukhopadhyay
}

Department of Agricultural Extension, Palli Siksha Bhavana (Institute of Agriculture), Visva-Bharati, Sriniketan, West Bengal, India

*Corresponding author: subir.kr.sinha12@gmail.com (ORCID ID: 0000-0002-2844-6325)

Received: 08-07-2019

Revised: 02-10-2019

Accepted: 24-11-2019

\begin{abstract}
The present study has been conducted in three districts of West Bengal, namely, Burdwan, Murshidabad and Nadia. The main objective of the present study was to assess the perception of beneficiaries about impact of MGNREGS on economic, social and societal empowerment of beneficiaries. The results of the study showed that respondents were primarily having low to semi-medium level of socio-economic orientation. The study revealed that through participation in MGNREGS activities, participants' average family income; worth of their possession of domestic material, animal resources and farm power could be increased. Moreover, respondents are having positive perception to the tune of semi-medium to medium level about the impact of their participation in MGNREGS activities on their economic, social and societal empowerment. Independent variables like, social participation, cosmopolites, membership of different social organisation, media exposure and respondents' education had significant association with their perception about economic, social and societal empowerment.

Highlights

(0 Annual income; possession of domestic materials, animal and farm power of beneficiaries increased.

( Beneficiaries had semi-medium to medium level of perception about impact of MGNREGS on economic, social and societal empowerment.

(0 Selected socio-economic variables had positive and significant association with beneficiaries' perception.
\end{abstract}

Keywords: MGNREGS, empowerment, economic, social, societal

Mahatma Gandhi National Rural Employment Guarantee Scheme (MGNREGS) came out of Mahatma Gandhi Rural Employment Guarantee Act (MGNREGA) is different from the earlier employment programme notified by the Government of India on $7^{\text {th }}$ September 2005 and implemented in all the rural districts of India in April 2008. Through this scheme, for the first time in the Indian history, every rural household have right to livelihood opportunity through guaranteed 100 days of employment in a financial year at their own village area. Provision of unemployment allowances are there in the scheme for not providing employment. MGNREGS is a powerful instrument for ensuring inclusive growth in rural India through its impact on social protection, livelihood security and democratic empowerment. Being different from other programmes MGNREGA is having integrated natural resource management livelihood generation perspectives. Looking at the budget provision, MGNREGS was provided with ₹ 34,699 crore during 2015-16, ₹ 55,000 crore during 2018-19 and ₹ 60,000 crore during 2019-20 (Economic Times, Agriculture, Feb 01, 2019). So far performance, MGNREGS has 3383.06 lakhs person days during 2018-19 out of which $31.43 \%, 8.43 \%$ and $48.1 \%$ were provided to SC, ST and women respectively. Average days of

How to cite this article: Sinha, S.K. and Mukhopadhyay, S.D. (2019) Perception of beneficiaries about impact of mgnregs on economic, social and societal empowerment. Economic Affairs, 64(4): 753-759. 
$\underset{A E S R A}{\int_{1}}$ Sinha and Mukhopadhyay

employment oer household was 77.43 during 201819 and 43.92 laks of total household were engaged in MGNREGS in the same year. (MGNREGA- 2005, Ministry of Rural Development, GoI, 2019).

Now question is how far MGNREGS could achieve its objectives of poverty alleviation by providing employment to rural masses? Different studies have been conducted to assess the impact of MGNREGS in this regard. Karthika (2015) depicted that MGNREGS plays a great role and has a positive impact on the rural development. Das (2016) reviewed the role of MGNREGA in rural employment and found that its role in inclusive growth of rural areas is significant. Dre'ze, J and C Oldiges (2011) concluded that the total expenditure and share of women was more or less in proportion with the increased coverage of the Act. They also found an increase of $15 \%$ in average wage rate along with increase in employment levels. Kharkwal and Kumar (2015) imposed that debts were found to increase along with asset possession though per capita saving declined. The value of socioeconomic index indicated that in the initial years of implementation of the programme, about 36 per cent of the beneficiary households were in poor socioeconomic strata which decreased to 12 per cent in 2013-14, while beneficiary households in good socioeconomic strata increased significantly.Pamecha and Sharma (2015) revealed that the programme has changed the lives of the beneficiaries.

Thomas \& Bhatia (2012) regarded MNREGA as an ambitious attempt to battle poverty by guaranteeing employment to those who demand work and capable in formation of capital in rural areas. Mathur (2008) depicted that MGNREGA could act as a great agent of socio-economic upliftment and providing livelihood security of poorest of the poor in India if implemented earnestly. The employment and the earning under MGNREGA should be treated as additional avenue for such households.

Understanding the necessity of assessing the impact of MGNREGS on the overall economic, social and societal empowerment of the rural people the present study has been conducted in three districts of West Bengal with broad objective to assess the perception of beneficiaries about impact of MGNREGS on economic, social and societal empowerment of beneficiaries.

\section{MATERIALS AND METHODS}

Three districts of West Bengal were selected for the present study. A multi-stage selection procedure was followed. At the first stage districts having registered beneficiaries more than state average i.e. 78.93 lakhs registered beneficiaries were selected. Twelve districts came up in that list. At the second stage district provided employment more than the state average i.e.1.82 lakhs of employment were identified. 11 districts were identified and they were categorized in three categories namely, High performance district (provided more than 3.55 lakhs employment), Medium performance (provided 3.42 lakhs of employment) and Low performance district (provided less than 2 lakhs of employment). Three districts from these three categories were selected for the present study namely, Murshidabad from High performance group (provided 3.66 lakhs employment), Burdwan from Medium performance group (provided 3.29 lakhs of employment) and Nadia from Low performance group (provided 1.81 lakhs employment). The selection of districts was based on MGNREGS data of West Bengal for the year 2009-2010. At the next level, from each district, one Block and two Gram Panchayats have been selected randomly form one Sub-Division. Thus, from Three Blocks of three districts, six numbers of Gram Panchayats have been selected with the consultation of Block Officials of the respective Blocks in respect of their active participation in the MGNREGS.

100 respondents from each Block of each selected districts (50 from each Gram Panchayat) was selected by following probability proportion method of sampling. The samples were taken on the basis of participation of population of general caste, schedule caste and schedule tribe, and also others from the six villages from three blocks of three districts in MGNREGS activities. Respondents who have participated in MGNREGS for at least five years were considered for selection. Thus, the total sample of respondents was 300 .

Data were collected on the major areas of socioeconomic orientation of respondents; respondents' Perception of Social, Economic and Societal Empowerment. For each broad area, a number of aspects have been considered. To ascertain the perception about economic empowerment, eleven aspects have been considered. These are, 'whether 
family income been increased through engagement in MGNREGS', 'whether standard of living improved through involvement in MGNREGS', 'whether expenditure incurred for your children's education increased through involvement in MGNREGS', 'whether household materials level improved', 'whether farm implements level improved', 'whether farm animal possession increased', 'whether family savings increased', 'whether man days involved increased', 'whether construct/ repair of house done through income MGNREGS', 'whether purchased any vehicle from income of MGNREGS', 'Does MGNREGS reduced job diversification especially during lean period', etc. Likewise, to ascertain the perception about social empowerment, seven aspects have been considered. These are, 'involvement in Gram Sabha meeting improved social image', 'involvement in selection of work to be conducted empowers you', 'involvement in selection of beneficiaries empowers', 'involvement in social audit team gives social prestige', 'involvement in supervision of work gives social weightage', 'involvement of budgeting of MGNREGS improves social power', 'discussing with people regarding MGNREGS gives a high social position', etc. And to ascertain the perception about societal empowerment, nine aspects have been considered. These are, 'Whether MGNREGS reduced migration of villagers for job', 'Does MGNREGS have negative impact on labour availability in Agricultural works', 'Does MGNREGS have negative impact on labour availability in household activities', 'Does MGNREGS have negative impact on labour availability on other vocation', 'Whether MGNREGS is having a positive impact on the society', 'Does MGNREGS enhance the group cohesion in the society', 'Does MGNREGS proliferate the political rivalry in the society', 'Does MGNREGS have positive impact on the Resource creation/improvement', 'Does MGNREGS helped in improving the overall quality of life' etc. Respondents were asked to mention their perception in a three-point scale (Hardikar, 1998) against each aspect containing Strongly Agree, Agree and Disagree with corresponding score of $3,2,1$. The collected data was compiled, tabulated, classified and further categorized for the systematic statistical analysis. The statistical tools used were frequency, mean, percentage, index value, standard deviation and regression. For each determinant the Index Value was calculated by the following formula,

Index Value $=\{($ Score Obtained $/$ Score max $) \times 100\}$ Index Value, ranging from 1-100 was classified into four different class intervals. Low (with Index Value 0-25), Semi-Medium (with Index Value 2650), Medium (51-75) and High (with Index Value (76-100.

\section{RESULTS AND DISCUSSION}

Results of the study is presented in different sections as follows:

\section{Socio-economic Orientation of the Respondents}

Table 1 depicts the broad socio-economic orientation of the respondents. It can be observed from the table that respondent's education and their family education status centered around middle to high school level for majority of the cases.

Further, it can be observed that Membership in social organization of the respondents as well as their Media Exposure were to the tune of low to medium level; whereas, Extent of Social Participation was found to be in low to medium level and in some cases, it was at the semi-medium level. Average annual family income before joining MGNREGS was ₹ 47162 in case of Burdwan district; ₹ 60947 in Nadia and ₹ 53619 in Murshidabad district. After five years of participation in MGNREGS these figures were found to be ₹ 68861, ₹ 74388 and ₹ 71301 respectively for Burdwan, Nadia and Murshidabad district.

Average domestic material possession was found to be worth of ₹ 11593.50, ₹ 5319.40 and ₹ 11610.50 for three districts before joining MGNREGS and these figures were, ₹ 16379, ₹ 7650.10 and ₹11610.50 respective for Burdwan, Nadia and Murshidabad districts after joining MGNREGS.

Average animal resources possession before joining MGNREGS was found to the worth of ₹ 5631, $₹ 3364$ and ₹ 4711.50 for three study districts and after joining MGNREGS these figures were changed to ₹ 8426, ₹ 5098 and ₹ 7045 respectively for Burdwan, Nadia and Murshidabad districts.

In case farm power possession by participants; the average possession was found to the worth of ₹ 4355.50, ₹ 3693 and ₹ 3553 for Burdwan, Nadia and 
Table 1: Socio Economic Orientation of the Respondents

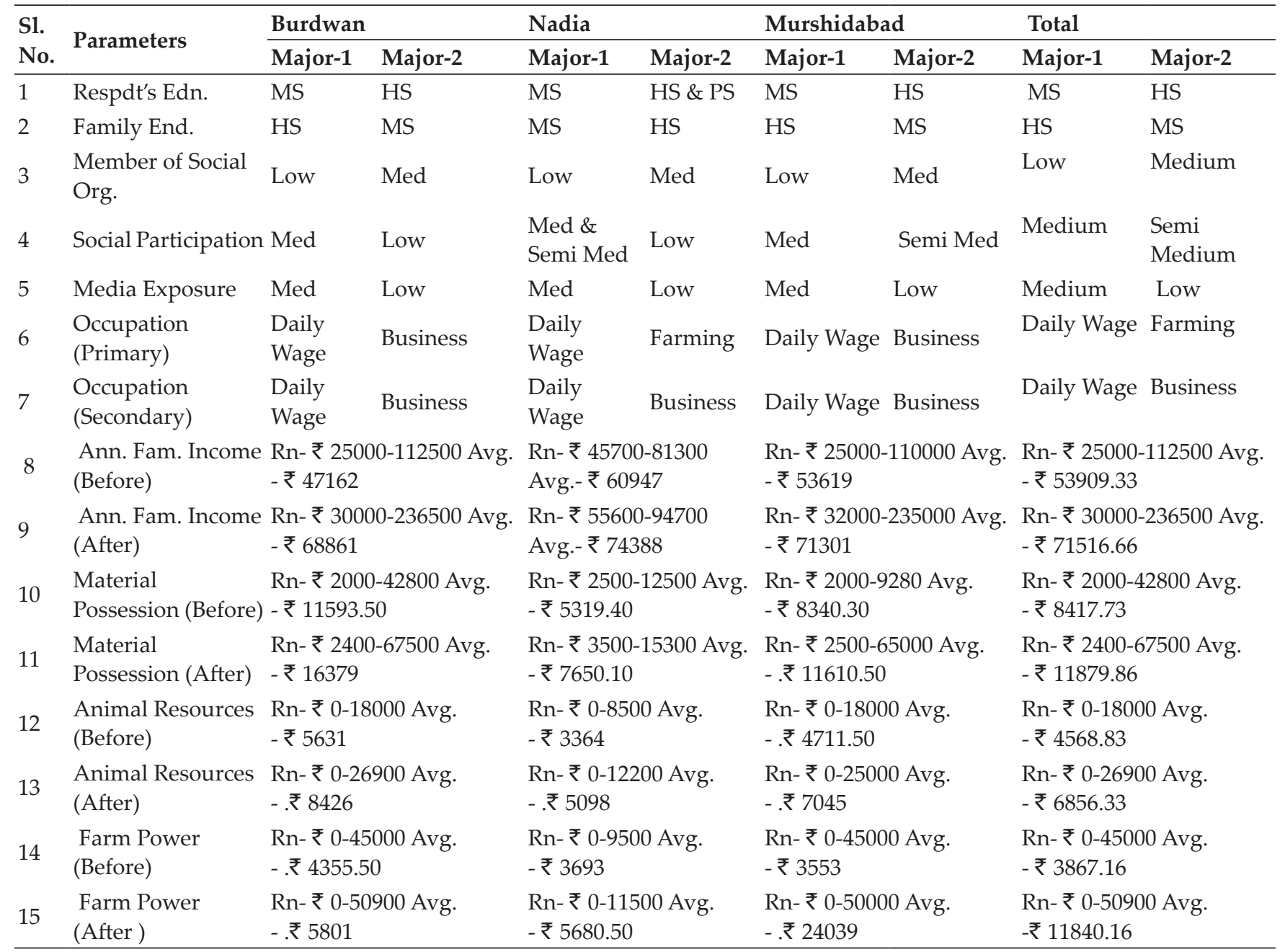

PS = Primary School, MS = Middle School, HS = High School, Edn.=Education, Org = Organisation

Murshidabad districts before joining MGNREGS which were changed to ₹ 5801, ₹ 5680.50 and ₹ 24039 for three districts after five years of their engagement in MGNREGS.

It is observed from the table participants average family income; worth of domestic material, animal resources and farm power have been increased for participants of all the study districts and total respondents after participating in MGNREGS activities which speaks in favour of positive impact of MGNREGS on the economy of participants.

\section{Perception of Respondents about Economic Empowerment Through Participation in MGNREGS.}

As mentioned in the methodology section eleven aspects were considered for ascertaining the perception of respondent about their Economic Empowerment through their participation in MGNREGS. Index value (EI) of each respondent was calculated by following the formula as given in methodology section. Further, distribution of respondent on the basis of the Index Value is presented in table 2 in four class intervals.

From table 2 it can be observed that majority of the respondents of study districts except Burdwan as well as total respondent had semi-medium level of perception about economic empowerments obtained from their involvement in MGNREGS activities $(69 \%, 53 \%$ and 55\% respectively for Nadia, Murshidabad and total respondents) followed by medium level of perception (29\%, 41\% and $40.33 \%$ respectively). In case of Burdwan district majority of the respondent was found to have medium level 
Table 2: Perception of Respondents about Economic Empowerment Through Participation in MGNREGS

\begin{tabular}{llllll}
\hline \multirow{2}{*}{ Economic Empowerment Index (EI) } & Burdwan & Nadia & Murshidabad & Total \\
\cline { 2 - 6 } & Total & Total & Total & 2 & 0.67 \\
\hline 0-25 (Low) & 0 & 0 & 2 & 55 \\
26-50 (Semi-Medium) & 43 & 69 & 53 & 41 & 121 \\
51-75 (Medium) & 51 & 29 & 4 & 12 & 4 \\
76-100 (High) & 6 & 2 & $\mathbf{1 0 0}$ & $\mathbf{3 0 0}$ \\
\hline Total & $\mathbf{1 0 0}$ & $\mathbf{1 0 0}$ & $\mathbf{1 0 0}$ \\
\hline
\end{tabular}

Table 3: Perception of Respondents about Social Empowerment Through Participation in MGNREGS

\begin{tabular}{|c|c|c|c|c|c|}
\hline \multirow{2}{*}{ Social Empowerment Index (SI) } & \multirow{2}{*}{$\begin{array}{l}\text { Burdwan } \\
\text { Total }\end{array}$} & \multirow{2}{*}{$\begin{array}{l}\text { Nadia } \\
\text { Total }\end{array}$} & \multirow{2}{*}{$\begin{array}{l}\text { Murshidabad } \\
\text { Total }\end{array}$} & \multirow{2}{*}{ Total } & \multirow{2}{*}{$\%$} \\
\hline & & & & & \\
\hline 0-25 (Low) & 20 & 0 & 11 & 31 & 10.33 \\
\hline 26-50 (Semi-Medium) & 52 & 21 & 37 & 110 & 36.67 \\
\hline 51-75 (Medium) & 28 & 46 & 34 & 108 & 36 \\
\hline 76-100 (High) & 0 & 33 & 18 & 51 & 17 \\
\hline Total & 100 & 100 & 100 & 300 & \\
\hline
\end{tabular}

of perception (51\%) followed by semi-medium level of perception (43\%). From the result it can be summarized that so far as the perception of the respondents are considered MGNREGS was found to have positive impact to the tune of semi-medium to medium level on the economic empowerment of the beneficiaries.

\section{Perception of Respondents about Social Empowerment Through Participation in MGNREGS}

As mentioned in the methodology section seven aspects were considered for ascertaining the perception of respondent about their Social Empowerment through their participation in MGNREGS. Index value (SI) of each respondent was calculated by following the formula as given in methodology section. Further, distribution of respondent on the basis of the Index Value is presented in table 3 in four class intervals. It can be observed from the table that respondents of Burdwan, Murshidabad and total respondents had semi-medium level of perception about the impact of MGNREGS on social empowerment (52\%, 37\% and $36.67 \%$ respectively) followed by medium level of perception $(28 \%, 34 \%$ and $36 \%$ respectively). In case of Nadia district, majority of the respondents (46\%) were found to have medium level of perception of impact of MGNREGS on social empowerment followed by semi-medium level of perception $(21 \%)$. Like the earlier section, in case of social empowerment, respondents were found to have a positive perception about the impact of MGNREGS on their social empowerment to the tune of semi-medium to medium level.

\section{Perception of Respondents about Societal Empowerment Through Participation in MGNREGS}

As mentioned in methodology section, nine aspects were considered for ascertaining the perception of respondent about their Societal Empowerment through their participation in MGNREGS. Index value (STI) of each respondent was calculated by following the formula as given in methodology section. Further, distribution of respondent on the basis of the Index Value is presented in table 4 in four class intervals.

From table 4 it can be observed that majority of the respondents of all three study districts and total respondents had medium level of perception about impact of MGNREGS on their societal empowerment (51\%, 29\%, 49\% and 43\% respectively for Burdwan, Nadia, Murshidabad and total respondents) followed by semi-medium level of perception $(29 \%$, $28 \%, 32 \%$ and $29.67 \%$ respectively for Burdwan, Nadia, Murshidabad and total respondents).

From all the results as mentioned above it can be concluded that respondents of study districts as a whole were having a positive perception about the impact of MGNREGS on their economic, social 
$\underset{A E S R A}{J_{1}}$ Sinha and Mukhopadhyay

Table 4: Perception of Respondents about Societal Empowerment Through Participation in MGNREGS

\begin{tabular}{|c|c|c|c|c|c|}
\hline \multirow{2}{*}{ Societal empowerment Index (STI) } & Burdwan & Nadia & Murshidabad & \multirow{2}{*}{ Total } & \multirow{2}{*}{$\%$} \\
\hline & Total & Total & Total & & \\
\hline 0-25 (Low) & 4 & 0 & 1 & 5 & 1.67 \\
\hline 26-50 (Semi -Medium) & 29 & 28 & 32 & 89 & 29.67 \\
\hline 51-75 (Medium) & 51 & 29 & 49 & 129 & 43.00 \\
\hline 76-100 (High) & 16 & 13 & 18 & 47 & 15.66 \\
\hline Total & 100 & 100 & 100 & 300 & 100 \\
\hline
\end{tabular}

and societal empowerments. That in turn speaks in favour of the modus operandi of MGNREGS that ultimately resulted into empowerment of the beneficiaries.

\section{Association Between Economic, Social and Societal Empowerment with Selected Independent Variables.}

Efforts were further made to ascertain the association between Economic, Social and Societal Empowerment with selected independent variables. For that purpose, Index Values of total respondents for Economic (EI), Social (SI) and Societal (STI) Empowerment have been considered as the dependent variables (Y1, Y2 and $\mathrm{Y} 3$ ) and Respondent's education (X1), Family education (X2), Membership of social Org. (X3), Extent of Social Participation (X4), Cosmopoliteness (X5), and Media Exposure (X6) have been considered as the independent variables. Multiple regression analyses were conducted results of which are presented below.

\section{1 Association Between Economic Empowerment with Selected Independent Variables}

Results for this section is present in table 5 . From the table it can be observed that X4 (Social Participation), X5 (Cosmopoliteness) and X6 (Media Exposure) had significant and positive association with the perception of respondents about impact of MGNREGS on economic empowerment at $1 \%$ and $5 \%$ level of significance with corresponding $\mathrm{R}^{2}$ (Adj) value of 0.64 .

Social participation, cosmopoliteness and media exposure is expected to have a greater bearing on forming perception of a person about something. In the present study, respondents having higher social participation, cosmpolitness and media exposure were able to compare their economic empowerment with others as well as could form their positive perception about the impact of MGNREGS on their economic empowerment.

Table 5: Xs Vs Economic Empowerment (Y1) of all Respondents

\begin{tabular}{lllll}
\hline Predictor & Coef & SE of Coef & $\mathbf{t}$ & $\mathbf{P}$ \\
\hline Constant & 11.8961 & 0.8904 & 13.36 & 0.000 \\
X1 & -0.0525 & 0.2016 & -0.26 & 0.795 \\
X2 & 0.1173 & 0.2406 & 0.49 & 0.626 \\
X3 & 0.0724 & 0.1352 & 0.54 & 0.593 \\
X4 & 0.13121 & 0.05772 & 2.27 & 0.024 \\
X5 & 0.01795 & 0.06142 & 3.29 & 0.170 \\
X6 & 0.01327 & 0.05810 & 3.23 & 0.019 \\
\hline
\end{tabular}

$R^{2}=0.72 ; R^{2}$ (adj) $=0.64$.

\section{2 Association Between Social Empowerment with Selected Independent Variables}

For this section Index value for Social Empowerment (SI) for total respondents have been taken as the dependent variable (Y2) and independent variables were same as in earlier case.

Table 6: Xs Vs Social Empowerment (Y2) of all Respondents

\begin{tabular}{lllll}
\hline Predictor & Coef & SE of Coef & $\mathbf{t}$ & $\mathbf{P}$ \\
\hline Constant & 4.9515 & 0.7811 & 6.34 & 0.000 \\
X1 & -0.4010 & 0.1769 & -2.27 & 0.024 \\
X2 & 0.2732 & 0.2111 & 1.29 & 0.197 \\
X3 & 0.2281 & 0.1186 & 2.92 & 0.055 \\
X4 & 0.24990 & 0.05064 & 4.94 & 0.000 \\
X5 & -0.02987 & 0.05389 & -0.55 & 0.580 \\
X6 & 0.04262 & 0.05097 & 0.84 & 0.404 \\
\hline$R^{2}=0.797 R^{2}$ (adj) $=0.71$. & & &
\end{tabular}

From table 6 it can be observed that X1 (Respondent's education), X3 (Membership of social 
Org), X4 (Social Participation) had positive and significant association with perception about social empowerment in $1 \%$ or $5 \%$ level of significance with adjusted $\mathrm{R}^{2}$ value of 0.71 .

Education always plays great role in formation of attitude or perception. Higher level of education of a person coupled with higher level of social participation and membership in different organisation helps forming proper understanding and perception of the respondents about social empowerment as the resultant effect of their participation in MGNREGS activities.

\subsection{Association Between Societal Empowerment with Selected Independent Variables}

For this section Index value for Societal Empowerment (STI) for total respondents have been considered as dependent variable (Y3) and the independent variables were same. Results are presented in table 7. From the table it can be observed that $\mathrm{X} 4$ (Social Participation), X5 (Cosmopoliteness) and X6 (Media Exposure) had positive and significant (1\% and $5 \%$ level of significance) with the perception of respondents about the impact of MGNREGS on their societal empowerment. The adjusted $\mathrm{R}^{2}$ value was found to be 0.699 .

The significant independent variables identified in the analysis are directly associated with societal interaction of a person and cumulatively helped the respondents to form a positive perception of MGNREGS on their societal empowerment.

Table 7: Xs Vs Societal Empowerment (Y5) of all Respondents

\begin{tabular}{lllll}
\hline Predictor & Coef & \multicolumn{2}{l}{ SE of Coef $\mathbf{t}$} & $\mathbf{P}$ \\
\hline Constant & 9.7445 & 0.7561 & 12.89 & 0.000 \\
X1 & -0.1472 & 0.1712 & -0.86 & 0.391 \\
X2 & 0.3093 & 0.2043 & 1.51 & 0.131 \\
X3 & -0.0070 & 0.1148 & -0.06 & 0.951 \\
X4 & 0.10825 & 0.04901 & 2.21 & 0.028 \\
X5 & 0.12208 & 0.05216 & 2.34 & 0.020 \\
X6 & 0.06752 & 0.04933 & 2.37 & 0.072 \\
\hline
\end{tabular}

$R^{2}=0.748 R^{2}($ adj $)=0.699$

\section{CONCLUSION}

Present study has been conducted in three districts of West Bengal. The results of the study showed that respondents were primarily having low to semi-medium level of socio-economic orientation. The study revealed that through participation in MGNREGS activities participants' average family income; worth of their possession of domestic material, animal resources and farm power could be increased. The study also showed that respondents are having positive perception to the tune of semimedium to medium level about the impact of their participation in MGNREGS activities on their economic, social and societal empowerment. The study further showed that intendent variables like, social participation, cosmopolites, membership of different social organisation, media exposure and respondents' education had significant association with their perception about economic, social and societal empowerment.

\section{REFERENCES}

Das, Darshana. 2016. Role of MGNREGA in Rural Employment: AStudy of Barpeta District of Assam, India. International Journal of Humanities E Social Science Studies, 2(6): 241-248.

Drèze, J. and Oldiges, C. 2011. NREGA: The official picture. In: R Khera, (Ed). The Battle for Employment Guarantee., New Delhi: Oxford University Press, pp. 21-43.

Economic Times, Agriculture, Feb 01, 2019.

Hardikar, D.P. 1998. Perfection of development programme derived by women beneficiaries of Ratnagiri District. Unpublished Ph. D Thesis, University of Dhaward.

Karthika, K.T. 2015. Impact of MGNREGA on Socio-Economic Development \& Women Empowerment. Journal of Business and Management, 17(7): 16-19.

Kharkwal, Sheela and Kumar, Anil. 2015. Socio-Economic impact of MGNREGA: Evidences from district of Udham Singh Nagar in Uttarakhand, India. Indian Journal of Economics and Development, 3(12): 1-10.

Mathur, L. 2008. Employment guarantee: progress so far. EPW, Vol. 52, December 29, 2007 to January 2008, pp. 17-20.

MGNREGA- 2005, Ministry of Rural Development, GoI, 2019.

Pamecha, Suman and Sharma, Indu. 2015. Socio-Economic Impact of MGNREGA - A Study Undertaken among Beneficiaries of 20 Villages of Dungarpur District of Rajasthan. International Journal of Scientific and Research Publications, 5(1): 1-4.

Thomas, Bigi and Bhatiaand Bhatia, Ruby. 2012. Impact of NREGA Scheme: A study on the overall quality of life of beneficiaries. Asia Pacific Journal of Social SciencesSciences, 4(2): 213-227. 
